\title{
A Method for Predicting the Influences of Bearing Support Stiffness and Position on the Vibrations of a Flexible Rotor System
}

\author{
Jing Liu \\ School of Marine Science and Technology, Northwestern Polytechnical University, Xi'an, 710072, People's Re- \\ public of China. \\ Key Laboratory for Unmanned Underwater Vehicle, Northwestern Polytechnical University, Xi'an, 710072, Peo- \\ ple's Republic of China. E-mail: jliu@cqu.edu.cn and jliu0922@nwpu.edu.cn \\ Changke Tang \\ College of Mechanical Engineering, Chongqing University, Chongqing, 400030, People's Republic of China.
}

(Received 11 April 2021; accepted 30 August 2021)

\begin{abstract}
The bearing support stiffness and position can greatly affect the vibrations of flexible rotor systems (FRSs). However, most previous works only focused on the effect of the bearing support stiffness on the critical speeds or modal characteristics including the natural frequencies and mode shapes of rigid rotor systems (RRSs). The previous studies missed the combined effects of the bearing support stiffness and position. To overcome this issue, an analytical method of a FRS based on the finite element (FE) method is proposed. Our model considers the bearing support stiffness and rotational inertia of FRS. The frequency equation of FRS is established for solving the critical speeds. The critical speeds and modal deformations of FRS from our model and the numerical model based on a commercial software are compared to verify the effectiveness of the presented method. The effects of the bearing support stiffness and position on the critical speeds of FRS are analyzed. The results show that the critical speeds are positively correlated with the bearing support stiffness. The critical speeds of FRS are also greatly affected by the bearing position. This study can provide some guidance for the optimization design method of bearing support stiffness and position in FRSs.
\end{abstract}

\section{NOMENCLATURE}

$\begin{array}{ll}\mathbf{u} & \text { displacement vector of FRS } \\ \dot{\mathbf{u}} & \text { velocity vector of the FRS } \\ \ddot{\mathbf{u}} & \text { acceleration vector of FRS } \\ \mathbf{M}_{1} & \text { assembled mass matrix of rotor } \\ \mathbf{G}_{1} & \text { assembled gyroscopic matrix of rotor } \\ \mathbf{K}_{1} & \text { assembled stiffness matrix of rotor } \\ \Omega & \text { rotational angular velocity } \\ \mathbf{M}_{s} & \text { mass matrix of each node } \\ \mathbf{M}_{\mathrm{d}} & \text { mass matrix of disk } \\ \mathbf{G}_{s} & \text { gyroscopic matrix of each node } \\ \mathbf{J} & \text { gyroscopic matrix of disk } \\ \mathbf{K}_{s} & \text { stiffness matrix of each node } \\ \omega & \text { whirling angular velocity } \\ K_{\mathrm{b}} & \text { support stiffness } \\ n_{\mathrm{FW} 1} & \text { first critical speed for FW } \\ x_{\mathrm{A}}, x_{\mathrm{B}}, x_{\mathrm{C}} & \text { variable of support positions A, B, and C } \\ \Delta x & \text { variable of support positions }\end{array}$

\section{INTRODUCTION}

Rotor systems in turbines, compressors, and turbojet engines are designed to be lighter and more flexible ones due to their working conditions. ${ }^{1}$ Thus, the system vibrations can be more difficult to control during the design processing of rotor systems. As key parameters for rotor systems, the unreasonable bearing support stiffness and position may produce unac- ceptable subcritical superharmonic responses when the rotor speed and system's natural frequencies are close. Thus, a clear analysis of the relationship between vibrations and rotor systems with different support stiffness and position is helpful for their optimal design.

Numerous previous works were focused on vibrations of rotor systems. For instance, Chen and $\mathrm{Wang}^{2}$ conducted a design optimization method for a rigid rotor system (RRS) based on the eigenvalues. Barrett and Flack ${ }^{3}$ proposed an experimental investigation to analyze the bearing support stiffness effect on the stability and unbalance vibrations of an RRS. Sinou et al. ${ }^{4}$ presented the finite element (FE) and experimental methods to investigate the bearing support stiffness effect on the critical speeds of an FRS. Sinou et al. ${ }^{5}$ developed an experimental analysis to study the modal characteristics including modal frequencies and shapes of an FRS for different speed cases. Nagasaka et al. ${ }^{6}$ discussed the damping ratio, lateral force, and unbalanced effects on the critical speeds for a uniform RRS. Dikmen et al. ${ }^{7}$ presented the FE and experimental methods to the bearing support stiffness effect on the modal characteristics of an FRS. Jalali et al. ${ }^{8}$ proposed an FE model to study the critical speeds, unbalance response, and operational deflection shapes of an FRS. Birchfield et al. ${ }^{9}$ used the transfer function approach to study the eigenvalues of a RRS considering the flexible foundations. Nagesh et al. ${ }^{10}$ developed the FE and experimental methods to analyze the modal characteristics of an FRS. Sinou and Thouverez ${ }^{11}$ presented an 
Table 1. Dimensional parameters of shaft.

\begin{tabular}{|l|l|l|l|l|l|l|l|}
\hline & $l_{1}$ & $l_{2}$ & $l_{3}$ & $l_{4}$ & $l_{5}$ & $l_{6}$ & $l_{7}$ \\
\hline Radius (mm) & 45.00 & 45.00 & 45.00 & 45.00 & 32.50 & 35.00 & 35.00 \\
Thickness (mm) & 49.94 & 49.94 & 49.94 & 49.94 & 26.05 & 30.21 & 30.21 \\
\hline
\end{tabular}

experimental method to study the bearing temperature effect on the critical speeds and unbalanced vibration of an FRS.

Additionally, Lazarus et al. ${ }^{12}$ introduced a FE model based on the modal analysis to discuss the unbalanced vibration of an FRS. Sopanen et al. ${ }^{13}$ introduced a numerical approach based on the multibody and FE methods to describe the superharmonic responses of an FRS. Wang et al. ${ }^{14}$ introduced an FE model to describe the shaft anisotropy effect on the whirling and forced responses for an FRS. Zou et al. ${ }^{15}$ developed a vibration method to describe the forward and backward frequencies of a FRS. Zhou et al. ${ }^{16}$ provided a rotor-bearing model to investigate the nonlinear characteristics. $\mathrm{Hu}$ and Palazzolo ${ }^{17}$ introduced an FE model including the gyroscopic and support stiffness of the bearings to model the modal characteristics of an FRS. Yang et al. ${ }^{18}$ provided an analytical method to study the bearing varying compliance on the dynamics of an RRS. Heidari and Safarpour ${ }^{19}$ proposed $H_{\infty}$ and $H_{2}$ approaches to obtain the optimum damping ratio and support stiffness for an FRS. Li et al. ${ }^{20}$ provided a general vibration method to study the dynamics for an FRS. Zheng et al. ${ }^{21}$ developed an FE model to study the bearing support stiffness and rotor material properties effects on the double frequency vibrations of an FRS. As seen in the above listed descriptions, most previous works only focused on the effect of the bearing support stiffness on the critical speeds of RRSs or modal characteristics including the natural frequencies and mode shapes. Few works focused on the combined effects of the bearing support stiffness and position on both the critical speeds and modal characteristics of an FRS.

This work proposes an analytical method of an FRS based on the FE method. The model considers the bearing support stiffness and rotational inertia of FRS. The rotor is modelled as Timoshenko beams. The contact stiffness in the bearings is obtained by using Hertzian contact method. The frequency equation of an FRS is established for solving the critical speeds. The critical speeds and modal deformations of the system from the presented model and the FE model based on a commercial software are compared to verify the effectiveness of our method. The effects of the bearing support stiffness and position on the critical speeds of an FRS are analyzed.

\section{A PROPOSED FE MODEL AND FREQUENCY EQUATION OF FRS}

An FE model of FRS is shown in Fig. 1. The shaft has three rigid disks. The three rigid disks have different masses and moments of inertia. The shaft and disks are rigidly connected. There are three support positions on the shaft. The three positions are located at the middle position and two ends of the shaft. Each support position only considers the bearing same stiffness along $X$ and $Y$ directions. The shaft and disks are made of 45 steel, and their density and Young's modulus are $7850 \mathrm{~kg} / \mathrm{m}^{3}$ and $209 \mathrm{GPa}$, respectively. The dimensional parameters of the shaft and disks are shown in Tables 1 and 2, respectively.
Table 2. Dimensional parameters of disks.

\begin{tabular}{|l|l|l|l|}
\hline & Disk 1 & Disk 2 & Disk 3 \\
\hline Outer radius $(\mathrm{mm})$ & 150 & 225 & 100 \\
Inner radius $(\mathrm{mm})$ & 45 & 45 & 35 \\
Length $(\mathrm{mm})$ & 20 & 30 & 30 \\
\hline
\end{tabular}

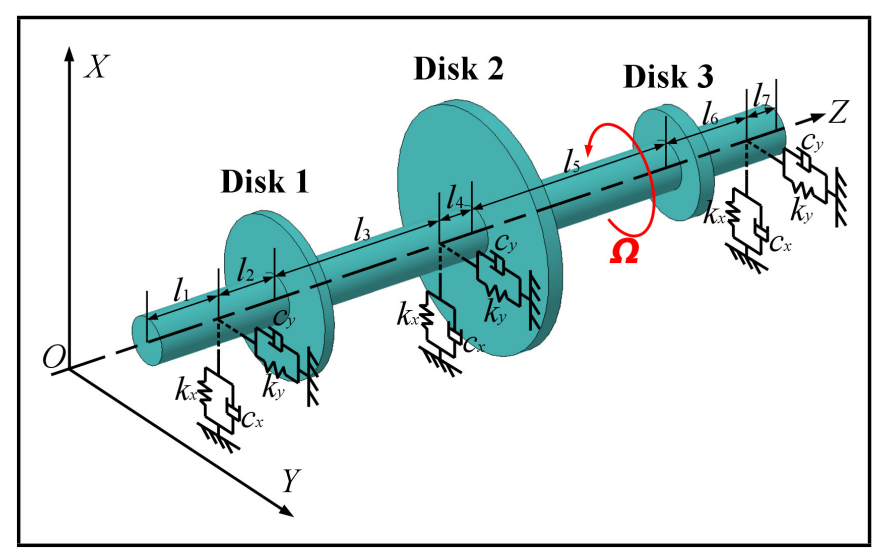

Figure 1. A FE model for the FRS.

To simulate the vibrations of the FRS, some assumptions are defined as follows.

1) The rigid connections between the shaft and bearing inner ring are used.

2) The bearing outer ring is rigidly supported, which is rigidly connected with bearing block.

3) It is a pure rolling state in the bearings.

4) The whole system is a healthy one.

5) The influences between the rolling elements and cage on the vibrations of system are ignored.

6) The influence of inertia of rolling elements is ignored.

7) The microscopic deformations of discretized shaft elements are ignored.

\subsection{A FE Model for an FRS}

According to the FE method in Ref., ${ }^{22}$ the equation for the proposed FE model for an FRS is given by:

$$
\left[\begin{array}{ll}
\mathbf{M}_{1} & \\
& \mathbf{M}_{1}
\end{array}\right]\{\ddot{\mathbf{u}}\}+\left[\begin{array}{ll}
\Omega \mathbf{J}_{1} & \\
& -\Omega \mathbf{J}_{1}
\end{array}\right]\{\dot{\mathbf{u}}\}+\left[\begin{array}{ll}
\mathbf{K}_{1} & \\
& \mathbf{K}_{1}
\end{array}\right]\{\mathbf{u}\}=\{\mathbf{0}\}
$$

where $\ddot{\mathbf{u}}, \dot{\mathbf{u}}$, and $\mathbf{u}$ are the acceleration, velocity, and displacement vectors of each node, and $\Omega$ denotes the rotational angular velocity; In Eq. (1), $\mathbf{J}_{1}$ denotes the assembled gyroscopic matrix, which includes the gyroscopic matrices of all nodes $\mathrm{G}_{\mathrm{s}}^{(\mathrm{i})}$ and gyroscopic matrix of the disk $\mathbf{J} ; \mathbf{M}_{1}$ describes the assembled mass matrix, which includes the mass matrices of all nodes $M_{s}^{(i)}(i=1,2, \ldots, 7)$ and mass matrix of the disk $M_{d} ; \mathbf{K}_{1}$ denotes the assembled stiffness matrix, which is composed by the stiffness matrices of all nodes $K_{\mathrm{s}}^{(\mathrm{i})}$; and $\{\boldsymbol{0}\}$ is the null vector. The details of $\mathbf{M}_{1}, \mathbf{J}_{1}$, and $\mathbf{K}_{1}$ are provided in Appendix A, as well as the relative parameters. The presented model is based on the finite element, Timoshenko beam and rotor dynamic theories. Firstly, the rotor shaft is discretized into several beam elements and the beam elements are considered as the Timoshenko beams. Secondly, the motion equations of beam elements are established based on Newton's second law. 


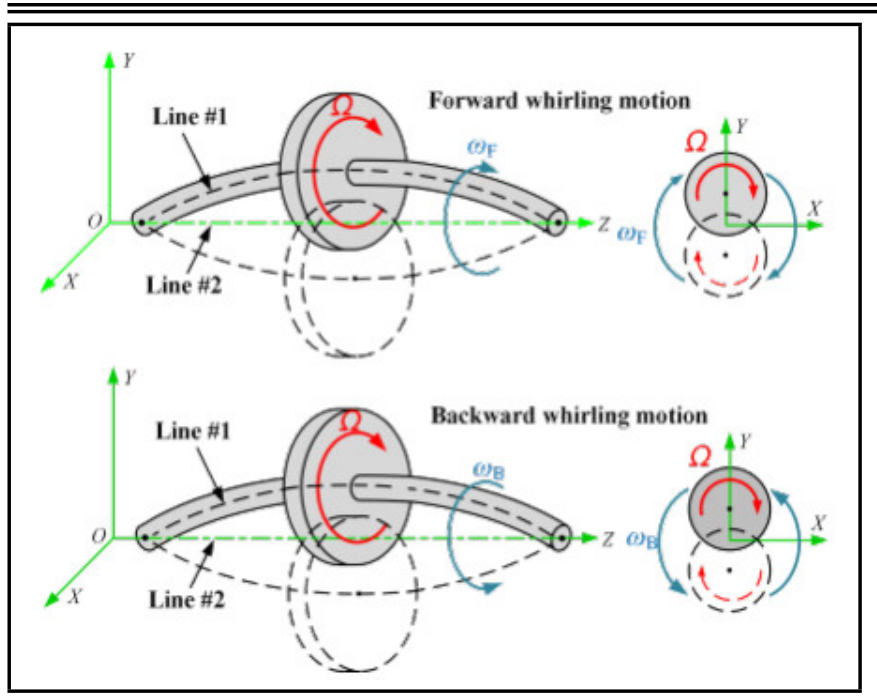

Figure 2. FW and BW motions of FRS.

Thirdly, the assemble motion equation of the flexible rotor system is established by combining the motion equations of beam elements. The vibration responses of each beam elements are obtained by solving the assemble motion equation.

\subsection{Frequency Equation of FRS}

When the gyro torque is considered, the shaft will be bent due to the unbalanced mass excitation. Both the orbit and rotary motions of rotor are formulated at the same time, where line \#1 is the axis of orbit motion and line \#2 is the axis of rotary motion as shown in Fig. 2. In Fig. 2, $\omega_{\mathrm{F}}$ and $\omega_{\mathrm{B}}$ are the orbit motion speeds in the forward and backward whirling directions, respectively; and $\Omega$ is the rotational speed of rotor. When the directions of $\omega_{\mathrm{F}}$ and $\Omega$ are same, it is the forward whirling $(\mathrm{FW})$ motion, and when the directions of $\omega_{\mathrm{B}}$ and $\Omega$ are different, it is the backward whirling (BW) motion.

The frequency equation for FRS is formulated as:

$$
\left|-\mathbf{M}_{1} \omega^{2}+\mathbf{J}_{1} \Omega \omega+\mathbf{K}_{1}\right|=0
$$

where $\omega$ is the whirling angular velocity. By solving Eq. (2), the frequencies for FW and BW motions can be obtained. These frequencies can reflect the variation of angular velocity of whirling motion during the changing processing of $\Omega$. If $\Omega= \pm \omega$ is substituted into Eq. (2), the critical speeds and natural frequencies for FW and BW motions can be solved, respectively.

\subsection{Model Validation}

In order to verify the accuracy of the proposed FE model of FRS, the critical speeds and vibrations from the proposed FE and numerical models are compared. The calculation code of the proposed FE model is developed by using MATLAB software. The commercial software used for model verification is ANSYS Workbench. In the software environment, the grid division is carried out for the 3D model of FRS; and the bearing elements are applied to the support positions. An FE model of FRS is established; and the critical speeds are obtained by the dynamic analysis.

The Campbell diagram derived from a numerical model using commercial software is shown in Fig. 3. The critical speeds

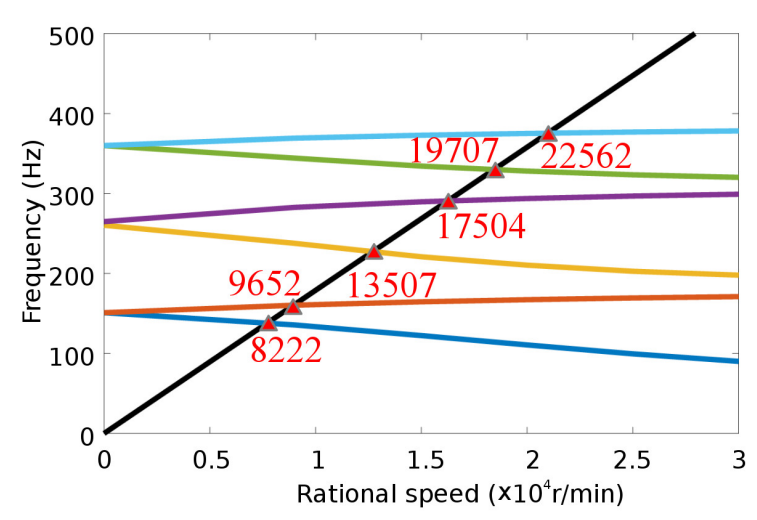

Figure 3. Campbell diagram of commercial software.

Table 3. Dimensional parameters of disks.

\begin{tabular}{|l|l|l|l|l|l|l||}
\hline Methods & \multicolumn{3}{|l|}{ FW critical speed (r/min) } & \multicolumn{3}{|l|}{ BW critical speed (r/min) } \\
& Mode & Mode & Mode & Mode & Mode & Mode \\
& 1 & 2 & 3 & 1 & 2 & 3 \\
\hline FE model & 10029 & 17887 & 22873 & 8674 & 14272 & 21379 \\
Numerical model & 9652 & 17504 & 22562 & 8222 & 13507 & 19707 \\
Differences & $3.8 \%$ & $2.1 \%$ & $1.4 \%$ & $5.2 \%$ & $5.4 \%$ & $7.8 \%$ \\
\hline
\end{tabular}

of FRS from the numerical model developed in the commercial software are provided in the Campbell diagram. The critical speeds and differences between the proposed FE and numerical models are listed in Table 3. Note that the differences between the proposed FE and numerical models are less than $10 \%$. The results can introduce some validation for the proposed FE model.

In Figs. 4 to 9, the mode shapes of FRS for proposed FE and numerical models at different critical speeds are compared. The first three natural frequencies of the proposed FE model for FW motion are $167 \mathrm{~Hz}, 298 \mathrm{~Hz}$, and $381 \mathrm{~Hz}$, respectively; and those for BW motion are $145 \mathrm{~Hz}, 238 \mathrm{~Hz}$, and $356 \mathrm{~Hz}$, respectively. The first three natural frequencies of numerical model from the commercial software for FW motion are 161 $\mathrm{Hz}, 292 \mathrm{~Hz}$, and $376 \mathrm{~Hz}$, respectively; and those for BW motion are $137 \mathrm{~Hz}, 225 \mathrm{~Hz}$, and $328 \mathrm{~Hz}$, respectively. For the FW motion, the differences of natural frequencies between the proposed FE model and numerical model are 3.6\%, 2.0\%, and $1.3 \%$, respectively. For the BW motion, the differences of nat-

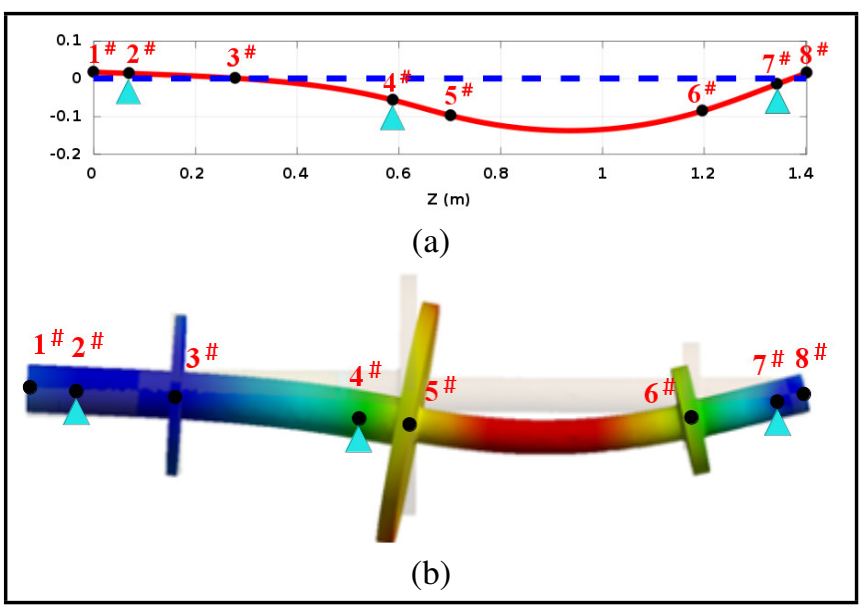

Figure 4. First mode shapes for BW motion from (a) the proposed FE model $(145 \mathrm{~Hz})$ and (b) numerical model $(137 \mathrm{~Hz})$. 


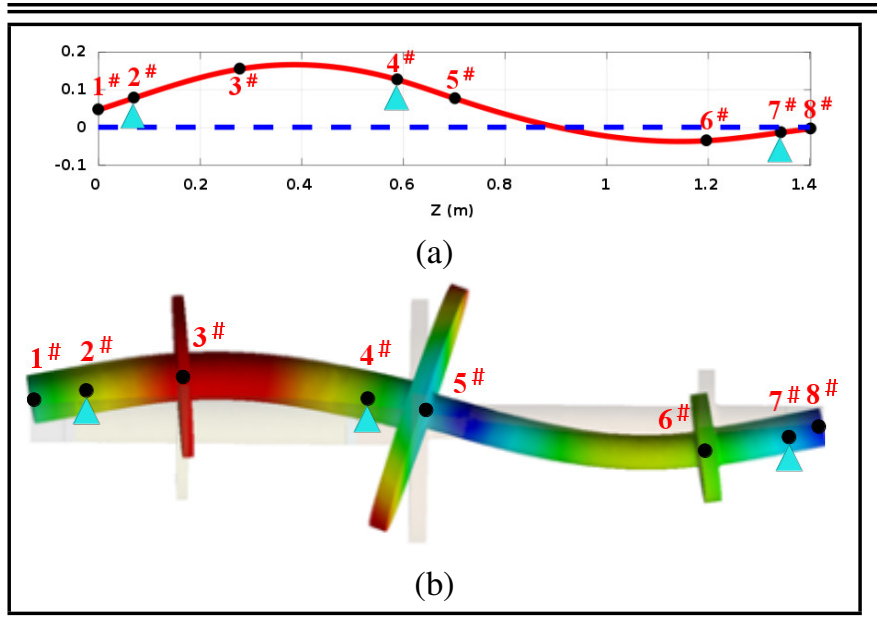

Figure 5. Second mode shapes for BW motion from (a) the proposed FE model $(238 \mathrm{~Hz})$ and (b) numerical model $(225 \mathrm{~Hz})$.

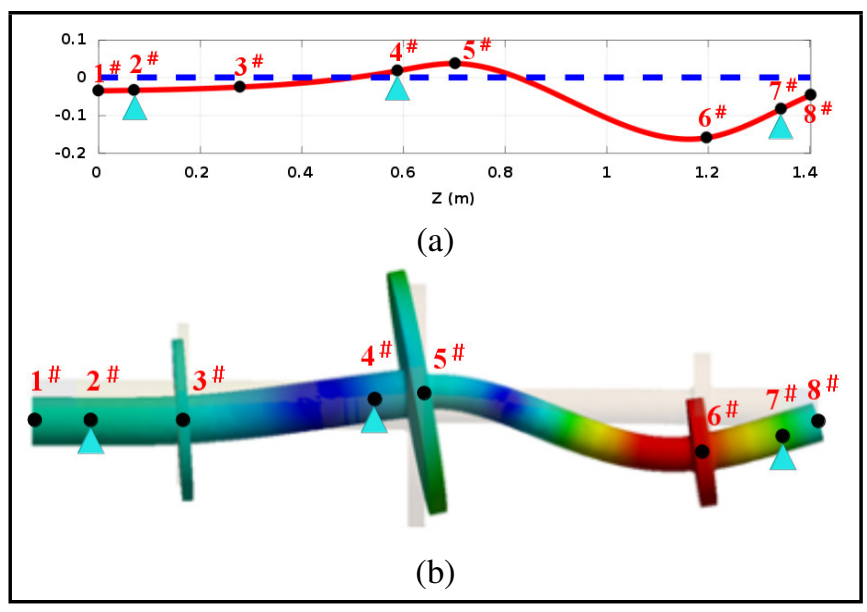

Figure 6. Third mode shapes for BW motion from (a) the proposed FE model $(356 \mathrm{~Hz})$ and (b) numerical model $(328 \mathrm{~Hz})$.

ural frequencies between the proposed FE model and numerical model are $5.5 \%, 5.5 \%$, and $7.9 \%$, respectively. Note that the vibrations for the proposed FE and numerical models from the commercial software are similar and their shapes match perfectly. As a consequence, the proposed FE model is an effective one for solving the critical speeds. In the FE model, the bearing stiffness is formulated by using four elastic spring with the constant stiffness coefficient. However, the bearing stiffness in the numerical model is formulated by the method given in equations (3) and (4). Moreover, the solid elements were used in the FE model, whose calculation method is different from that of the Timoshenko beam element used in the numerical model. The above differences of the bearing stiffness and element types may cause the differences of the natural frequencies from the FE and numerical model.

\section{NUMERICAL ANALYSES}

To formulate the bearing stiffness effect on the critical speeds of FRS, the first critical speeds for FW motion are calculated by Eq. (2) for different bearing stiffness cases. To analyze the effects of support positions A, B, and C on the critical speeds of FRS, three support position cases are discussed as shown in Fig. 10, where their variation ranges $x_{\mathrm{A}}, x_{\mathrm{B}}$, and $x_{\mathrm{C}}$ are defined be from $0 \mathrm{~mm}$ to $40 \mathrm{~mm}$. Under the above conditions, the first critical speeds for FW motion are calculated

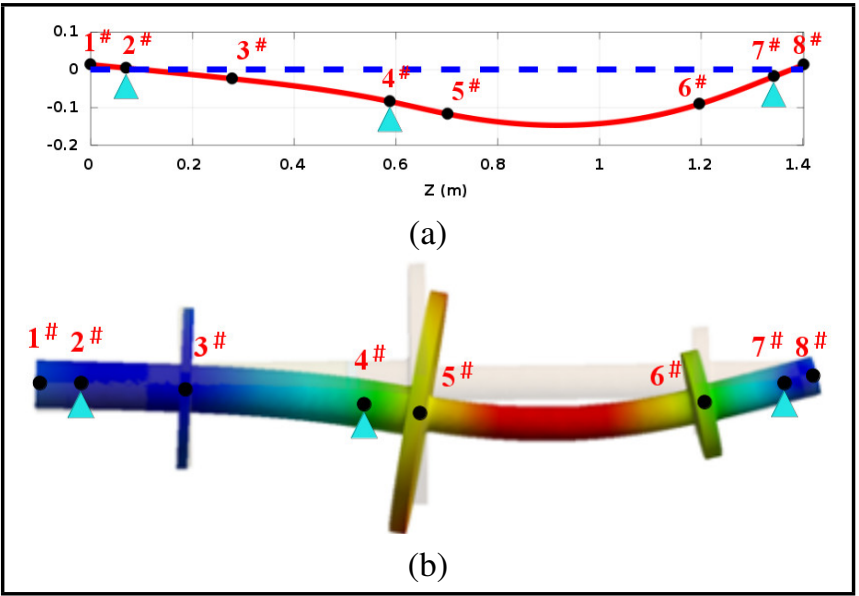

Figure 7. First mode shapes for FW motion from (a) the proposed FE model $(167 \mathrm{~Hz})$ and (b) numerical model $(161 \mathrm{~Hz})$.

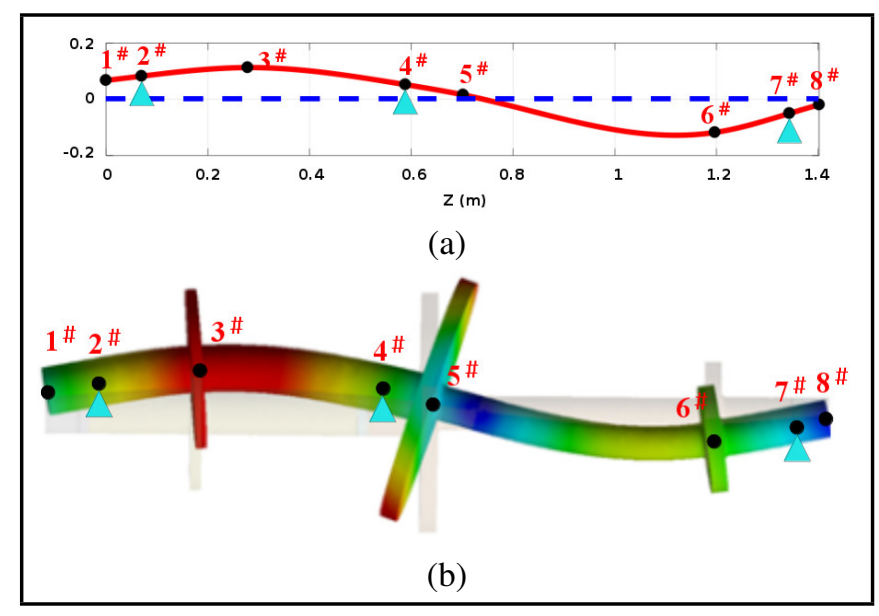

Figure 8. Second mode shapes for FW motion from (a) the proposed FE model $(298 \mathrm{~Hz})$ and (b) numerical model $(292 \mathrm{~Hz})$.

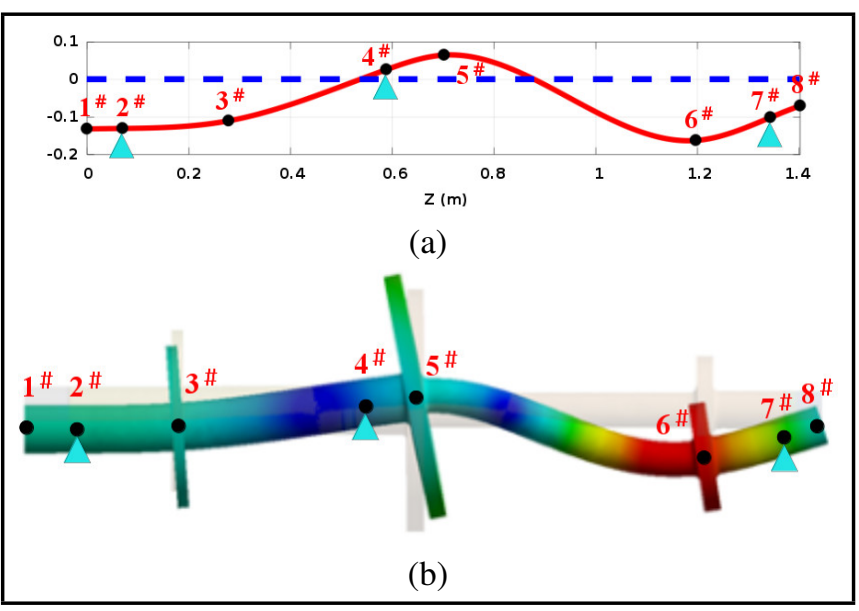

Figure 9. Third mode shapes for FW motion from (a) the proposed FE model $(381 \mathrm{~Hz})$ and (b) numerical model $(376 \mathrm{~Hz})$.

International Journal of Acoustics and Vibration, Vol. 26, No. 4, 2021 


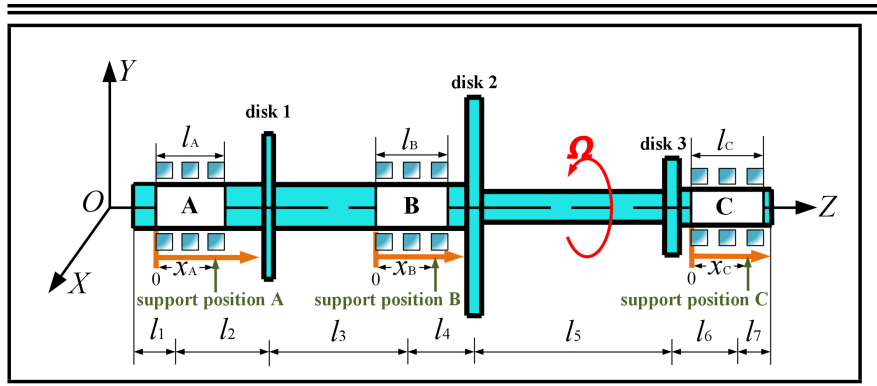

Figure 10. Effect of the support stiffness on the critical speeds of FRS.

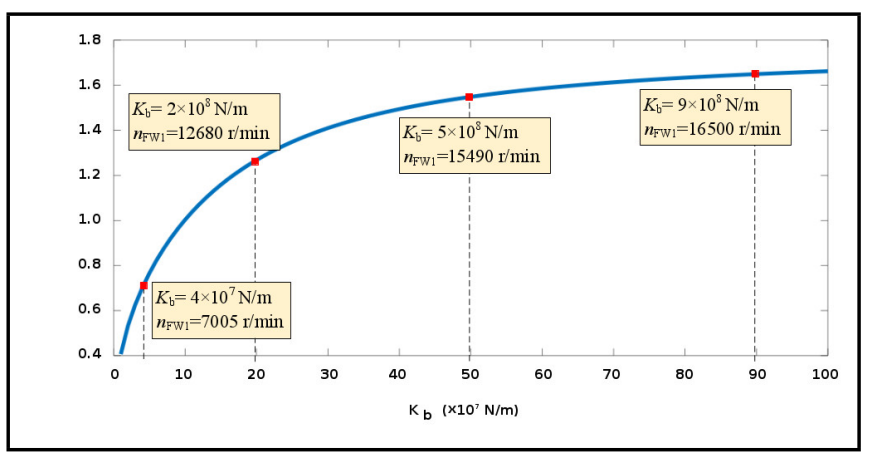

Figure 11. Effect of the support stiffness on the critical speeds of FRS.

by Eq. (2) for different support position cases.

In this work, the changes of the support stiffness and positions are used to change the critical speeds of the shaft, which purpose is to obtain the reasonable critical speeds of the design system. In this study, the operating speed of the system is about $11000 \mathrm{r} / \mathrm{min}$.

\subsection{Support Stiffness Effect on the Critical Speeds of FRS}

The support stiffness effect on the first critical speed for FW motion is shown in Fig. 11. The support stiffness is from $1 \times 10^{7}$ to $1 \times 10^{9} \mathrm{~N} / \mathrm{m}$. In Fig. 11 , the first critical speed for FW motion increases with the increment of support stiffness. When $K_{\mathrm{b}}$ is larger than $5 \times 10^{8} \mathrm{~N} / \mathrm{m}$, the increasing rate of first critical speed will slow down. It seems that the critical speeds are positively correlated with the bearing support stiffness.

As the method given in Refs., ${ }^{22,23}$ the total contact stiffness of bearing can be calculated by:

$$
k_{t o t}=\frac{1}{\left[\left(1 / k_{b i n}\right)^{1 / n}+\left(1 / k_{\text {bout }}\right)^{1 / n}\right]^{n}}
$$

where $k_{\text {bin }}$ and $k_{\text {bout }}$ are the contact stiffness between the rolling element and two races, respectively; $n$ is the load-deflection coefficient. Here, the bearing stiffness is depended on the geometric sizes of the rolling element and raceways, as well as the material parameters (such as elastic modulus, density, and Poison's ratio) of bearing components. ${ }^{24}$ Moreover, the manufacturing errors, defects, and lubricating conditions can also affect the bearing stiffness as given in Refs. ${ }^{24,25}$ More details for the calculation methods for the bearing stiffness can be found in Refs. ${ }^{22,23}$ The contact force for each rolling element is given as:

$$
F_{t o t}=k_{t o t} \delta^{n}
$$

The total bearing forces in different translational directions can be calculated as a sum of all individual roller forces.

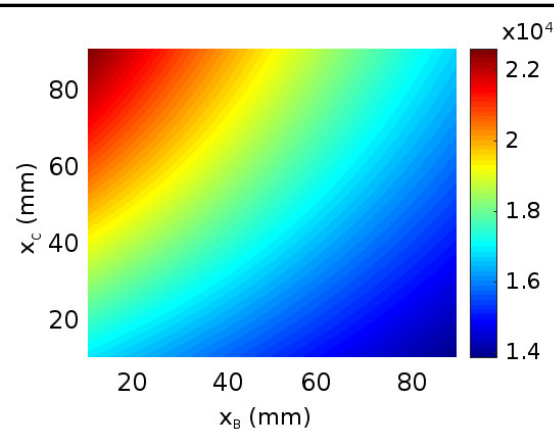

(a)

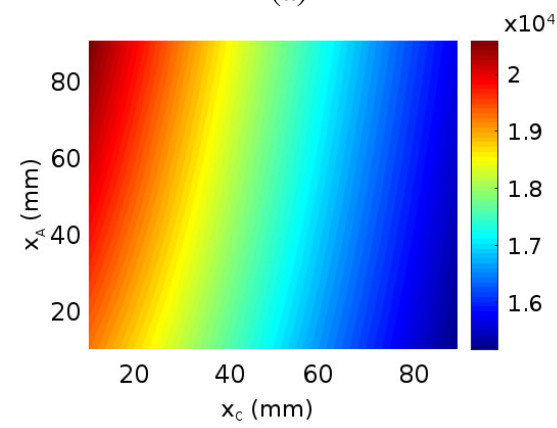

(b)

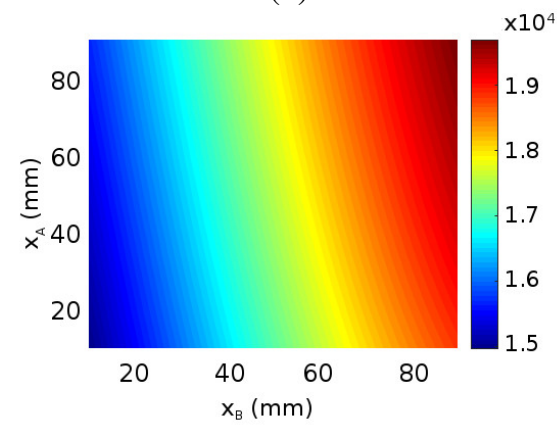

(c)

Figure 12. First critical speeds for FW motion of FRS when (a) $x_{\mathrm{A}}=40 \mathrm{~mm}$, (b) $x_{\mathrm{B}}=40 \mathrm{~mm}$, and (c) $x_{\mathrm{C}}=40 \mathrm{~mm}$.

\subsection{Support Position Effect on the Critical Speeds of FRS}

\subsubsection{Case one}

For case one, one support position is fixed; and the other two support positions are variable. The effect of this support position case on the first critical speed for FW motion is depicted in Fig. 12. In Fig. 12(a), $x_{\mathrm{A}}$ is fixed at $40 \mathrm{~mm}$, the first critical speed of FRS increases with $x_{\mathrm{B}}$ decrement; and the first critical speed of FRS increases with $x_{\mathrm{C}}$ increment. In Fig. 12(b), $x_{\mathrm{B}}$ is fixed at $40 \mathrm{~mm}$, the first critical speed of FRS increases with the increment of $x_{\mathrm{A}}$; and the first critical speed of FRS increases with $x_{\mathrm{C}}$ decrement. In Fig. 12(c), $x_{\mathrm{C}}$ is fixed at $40 \mathrm{~mm}$, the first critical speed of FRS increases with $x_{\mathrm{A}}$ increment; and the first critical speed of FRS increases with $x_{\mathrm{B}}$ increment. Figure 12 gives that the first critical speed of FRS is greatly affected by the bearing support positions. Thus, the support position optimization can be helpful for controlling the first critical speed and relative vibrations. 


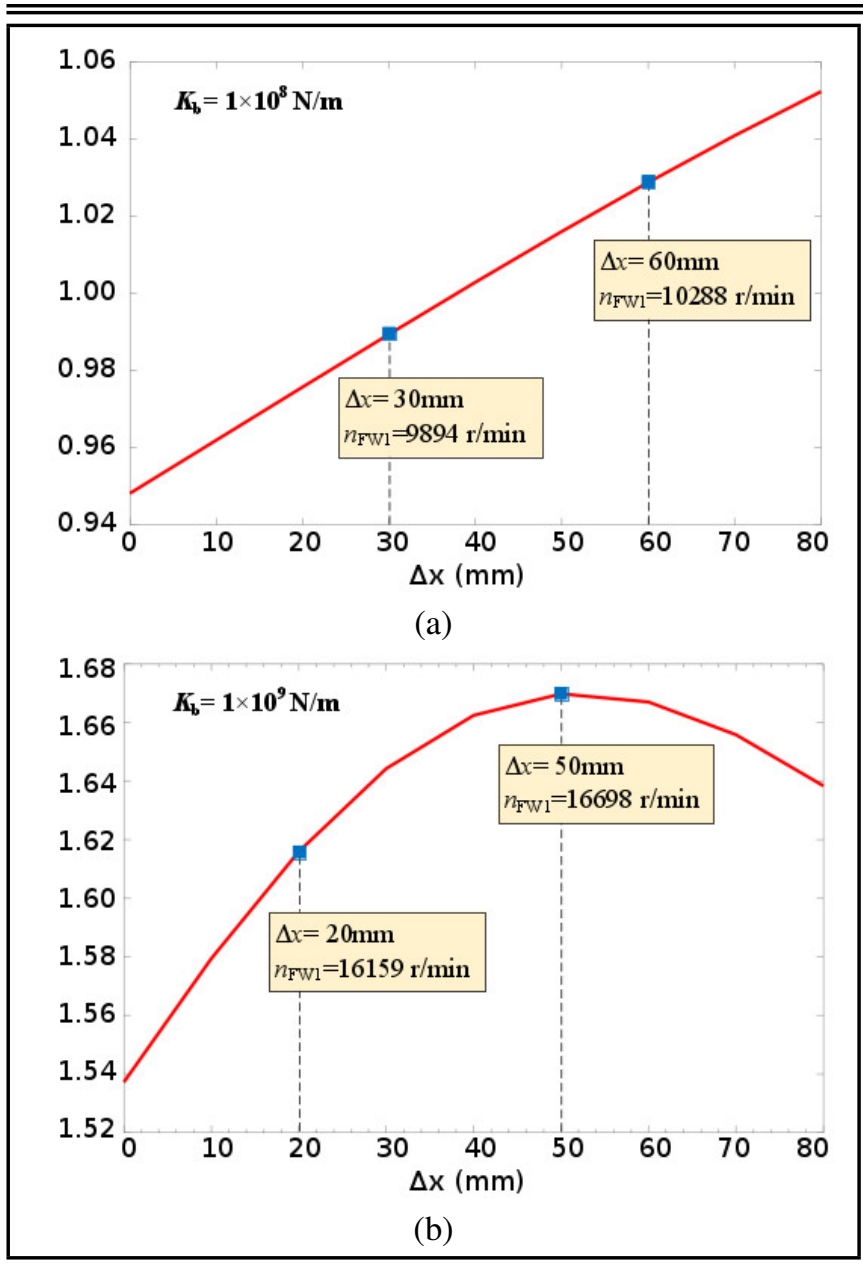

Figure 13. First critical speeds for FW motion of FRS when (a) $K_{\mathrm{b}}=1 \times 108$ $\mathrm{N} / \mathrm{m}$, and (b) $K_{\mathrm{b}}=1 \times 10^{9} \mathrm{~N} / \mathrm{m}$.

\subsubsection{Case two}

For case two, the variations of three positions $x_{\mathrm{A}}, x_{\mathrm{B}}$, and $x_{\mathrm{C}}$ are same, whose values are defined as $\Delta x$. Fig. 13 depicts the effect of this support position case on the first critical speed for FW motion. In Fig. $13(\mathrm{a}), K_{\mathrm{b}}=1 \times 10^{8} \mathrm{~N} / \mathrm{m}$, the first critical speed for FW motion increases with the variation $\Delta x$ increment. In Fig. 13(b), $K_{\mathrm{b}}=1 \times 10^{9} \mathrm{~N} / \mathrm{m}$, when $\Delta x$ is less than 50 $\mathrm{mm}$, the first critical speed for FW motion increases with the increment of $\Delta x$; when $\Delta x$ is $50 \mathrm{~mm}$, the first critical speed for $\mathrm{FW}$ motion reaches the maximum one; when $\Delta x$ is larger than $50 \mathrm{~mm}$, the first critical speed for FW motion decreases with the increment of $\Delta x$. Figure 13 also gives that the first critical speed of FRS is greatly affected by the bearing support positions. Similarly, the results show that the support position optimization can be helpful for controlling the first critical speed and relative vibrations.

\subsubsection{Case three}

For case three, the variations of two positions are same; and the other one position is different ( effect of this support position case on the first critical speed for FW motion is depicted in Fig. 14. In Fig. 14(a), $x_{\mathrm{B}}$ and $x_{\mathrm{C}}$ are same, the first critical speed for FW motion increases when $x_{\mathrm{B}}$ and $x_{\mathrm{C}}$ are close to $42 \mathrm{~mm}$; and the first critical speed for FW motion increases with the increment of $x_{\mathrm{A}}$. In Fig. 14(b), $x_{\mathrm{A}}$ and $x_{\mathrm{C}}$ are same, the first critical speed for FW motion increases with the decrements of $x_{\mathrm{A}}$ and $x_{\mathrm{C}}$; and the first critical

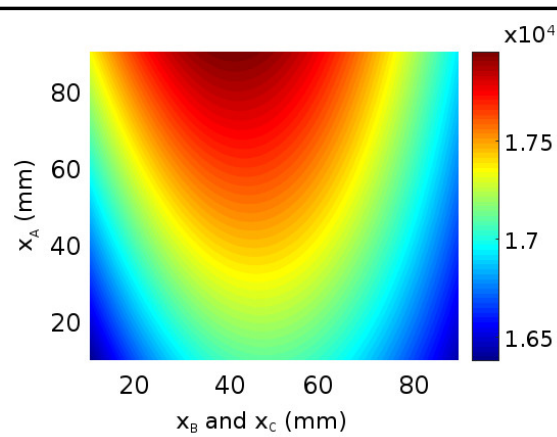

(a)

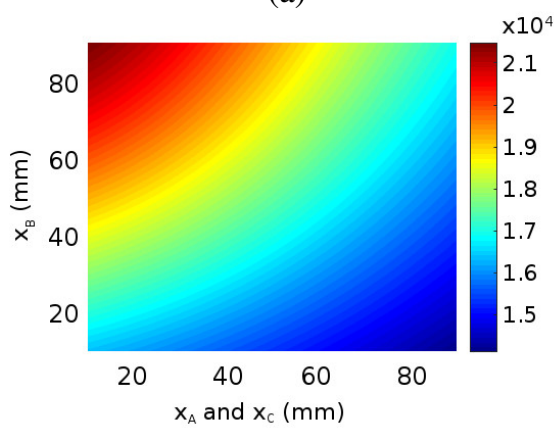

(b)

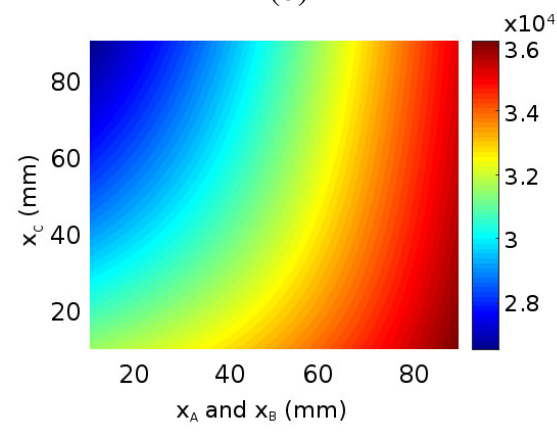

(c)

Figure 14. First critical speeds for FW motion of FRS when (a) $x_{\mathrm{B}}$ and $x_{\mathrm{C}}$, (b) $x_{\mathrm{A}}$ and $x_{\mathrm{C}}$, and (c) $x_{\mathrm{A}}$ and $x_{\mathrm{B}}$ are same.

speed for FW motion increases with the increment of $x_{\mathrm{B}}$. In Fig. 14(c), $x_{\mathrm{A}}$ and $x_{\mathrm{B}}$ are same, the first critical speed for FW motion increases with the increments of $x_{\mathrm{A}}$ and $x_{\mathrm{B}}$; and the first critical speed for FW motion increases with the decrement of $x_{\mathrm{C}}$. Figure 14 gives that the first critical speed of FRS is greatly affected by the bearing support positions too. Moreover, the results also depict that the support position optimization can be helpful for controlling the first critical speed and relative vibrations.

\section{CONCLUSIONS}

This study proposes an analytical FE model of an FRS based on the FE method in the literature. The proposed model considered the bearing support stiffness and rotational inertia of FRS. The frequency equation of an FRS was established for solving the critical speeds. The critical speeds, mode shapes, and natural frequencies of the system from the proposed FE model and a numerical model based on commercial software were compared to verify the effectiveness of the proposed FE model. The effects of the bearing support stiffness and position on the critical speeds of FRS were analyzed. The results 
Table A1. $i$ th Timoshenko beam element parameters.

\begin{tabular}{|l|l|}
\hline Parameters & Value \\
\hline length & $l$ \\
radius & $r$ \\
elastic modulus & $E$ \\
Moment of inertia & $I$ \\
Poisson's ratio & $\mu$ \\
Rotation speed & $\omega$ \\
\hline
\end{tabular}

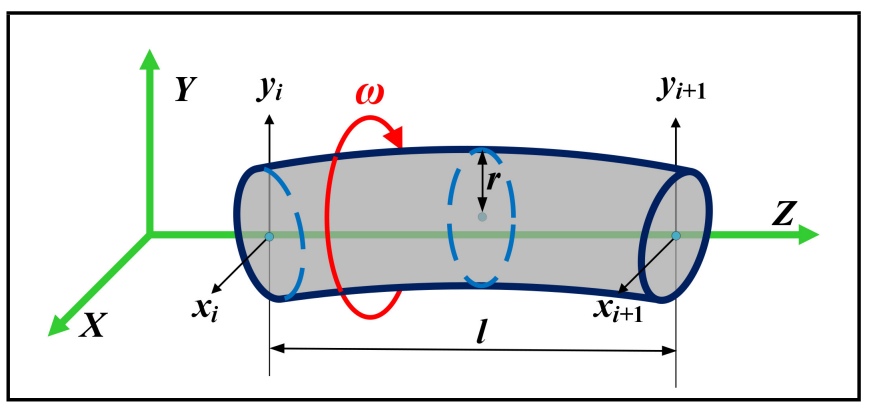

Figure A1. $i$ th Timoshenko beam element.

showed that the critical speeds were positively correlated with the bearing support stiffness. The critical speeds of an FRS were greatly affected by the bearing support position too. The bearing support positions could be located near the nodes of the mode shapes. A reasonable rotor system with a lower vibration level was obtained by optimizing the bearing support positions and bearing stiffness. Thus, the support position optimization can be helpful for controlling the first critical speed and relative vibrations. This study provided some guidance for the optimization design method of bearing support stiffness and position in the FRSs.

\section{ACKNOWLEDGEMENTS}

Supported by National Natural Science Foundation of China (No. 51975068 and 52175120), and Fundamental Research Funds for Central Universities (No. 3102020HHZY030001).

\section{COMPETING INTERESTS}

The authors have no conflicts of interest to this work.

\section{APPENDIX A}

Based on the FE method, a shaft in a FRS can be divided into $i$ Timoshenko beam elements. The parameters of $i$ th Timoshenko beam element are listed in Table A.1 and Fig. A.1.

The mass matrix $\mathrm{M}_{\mathrm{s}}^{(\mathrm{i})}$, gyroscopic matrix $G_{s}(i)$ and stiffness matrix $K_{s}(i)$ of the beam element are as follows.
(1) The mass matrix for beam element $M_{s}(i)$ is defined as:

$$
\mathbf{M}_{\mathrm{s}}^{(i)}=\mathbf{M}_{\mathrm{sT}}^{(i)}+\mathbf{M}_{\mathrm{sR}}^{(i)}
$$

where $M_{s T}(i)$ and $M_{s R}(i)$ are:

$$
\begin{aligned}
& \mathbf{M}_{\mathrm{sT}}^{(i)}=\frac{\mu l}{420}\left[\begin{array}{cccc}
156 & 22 l & 54 & -13 l \\
& 4 l^{2} & 13 l & -3 l^{2} \\
& & 156 & -22 l \\
\mathrm{sym} & & & 4 l^{2}
\end{array}\right] \\
& \mathbf{M}_{\mathrm{sR}}^{(i)}=\frac{\mu r^{2}}{120 l}\left[\begin{array}{cccc}
36 & 3 l & -36 & 3 l \\
& 4 l^{2} & -3 l & -l^{2} \\
& & 36 & -3 l \\
\text { sym } & & & 4 l^{2}
\end{array}\right]
\end{aligned}
$$

(2) The gyroscopic matrix for beam element $G_{s}^{(i)}$ is defined by:

$$
G_{\mathrm{s}}^{(i)}=\omega \mathbf{J}_{\mathrm{s}}^{(i)}=\frac{\mu \omega r^{2}}{60 l}\left[\begin{array}{cccc}
60 & 3 l & -36 & 3 l \\
& 4 l^{2} & -3 l & -l^{2} \\
& & 36 & -3 l \\
\mathrm{sym} & & & 4 l^{2}
\end{array}\right]
$$

(3) The stiffness matrix of beam element $K_{s}(i)$ is defined by:

$$
\mathbf{K}_{\mathrm{s}}^{(i)}=\frac{E I}{l^{3}}\left[\begin{array}{cccc}
12 & 6 l & -12 & 6 l \\
& 4 l^{2} & -6 l & 2 l^{2} \\
& & 12 & -6 l \\
\operatorname{sym} & & & 4 l^{2}
\end{array}\right]
$$

Moreover, $M_{s}(i), G_{s}(i)$ and $K_{s}(i)$ are divided into four matrices as follows:

$$
\begin{aligned}
\mathbf{M}_{\mathrm{s}}^{(i)} & =\left[\begin{array}{ll}
\mathbf{m}_{11}^{(i)} & \mathbf{m}_{12}^{(i)} \\
\mathbf{m}_{21}^{(i)} & \mathbf{m}_{22}^{(i)}
\end{array}\right], \\
\mathbf{J}_{\mathrm{s}}^{(i)} & =\left[\begin{array}{ll}
\mathbf{J}_{11}^{(i)} & \mathbf{J}_{12}^{(i)} \\
\mathbf{J}_{21}^{(i)} & \mathbf{J}_{22}^{(i)}
\end{array}\right], \\
\mathbf{K}_{\mathrm{s}}^{(i)} & =\left[\begin{array}{ll}
\mathbf{K}_{11}^{(i)} & \mathbf{K}_{12}^{(i)} \\
\mathbf{K}_{21}^{(i)} & \mathbf{K}_{22}^{(i)}
\end{array}\right]
\end{aligned}
$$

For a FRS with 11 nodes connected by 7 beam elements, gyroscopic matrix $\mathrm{G}_{\mathrm{s}}^{(\mathrm{i})}$, mass matrix $M_{s}(i)$, and stiffness matrix $K_{s}(i)$ of each element can be integrated to the assembled mass matrix $\mathbf{M}_{1}$, the assembled gyroscopic matrix $\mathbf{G}_{1}$ and assembled stiffness matrix $\mathbf{K}_{1}$. The specific compositions are:

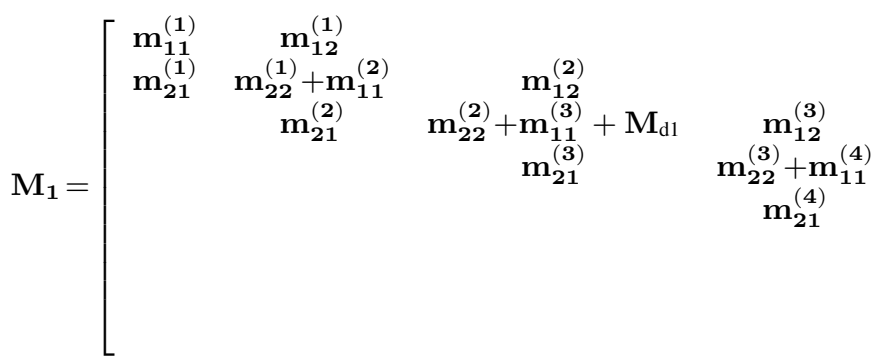

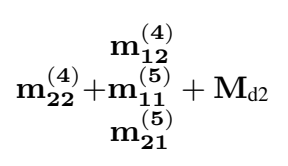

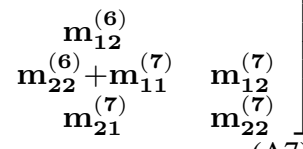




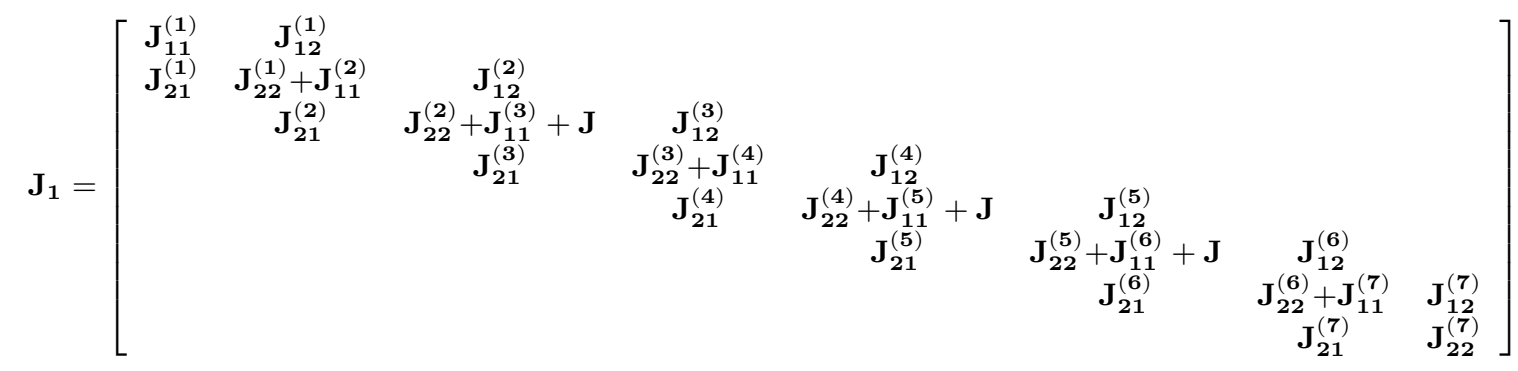

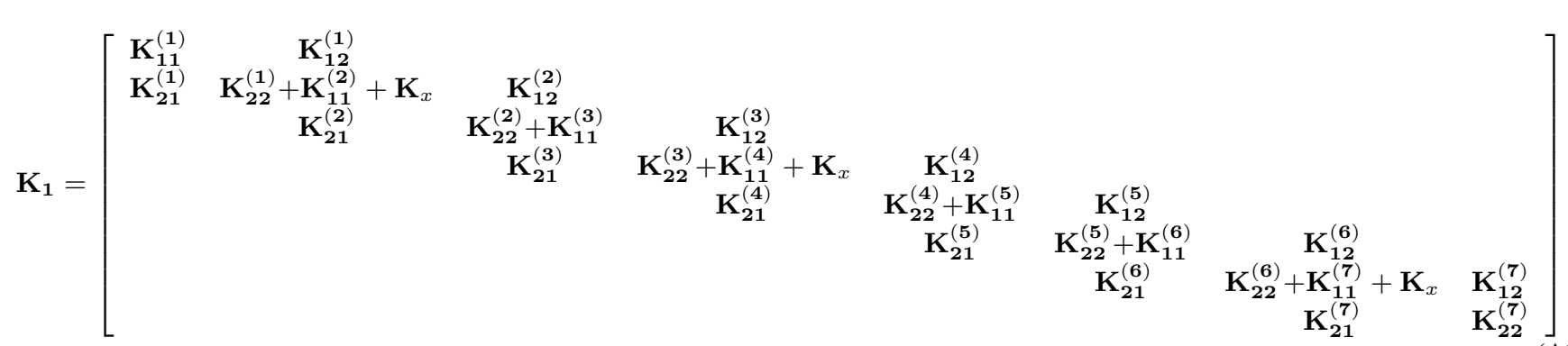

where the disk mass matrix $M_{d}$, disk gyroscopic matrix $\mathbf{J}$, and stiffness matrix of bearing $\mathbf{K}_{x}$ are represented as:

$$
\begin{aligned}
\mathbf{M}_{\mathrm{d}} & =\left[\begin{array}{cc}
m_{\mathrm{d}} & 0 \\
0 & J_{\mathrm{d}}
\end{array}\right] \\
\mathbf{J} & =\left[\begin{array}{cc}
0 & 0 \\
0 & J_{\mathrm{p}}
\end{array}\right] \\
\mathbf{K}_{x} & =\left[\begin{array}{cc}
K_{\mathrm{b}} & 0 \\
0 & 0
\end{array}\right]
\end{aligned}
$$

where $m_{\mathrm{d}}, J_{\mathrm{d}}, J_{\mathrm{p}}$, and $K_{\mathrm{b}}$ are the mass, diametral moment of inertia, polar moment of inertia for disk and support stiffness in the $X$ direction, whose calculation methods are given in Refs. ${ }^{25-29}$ for different bearing types.

\section{REFERENCES}

1 Liu J., Xu Z., Zhou L., et al. A statistical feature investigation of the spalling propagation assessment for a ball bearing. Mechanism and Machine Theory, 131, 336-350, (2019). https://dx.doi.org/10.1016/j.mechmachtheory.2018.10.007

2 Chen T. Y., Wang B. P. Optimum design of rotor-bearing systems with eigenvalue constraints. Journal of Engineering for Gas Turbines and Power, 115(2), 256-260, (1993). https://dx.doi.org/10.1115/1.2906702

3 Barrett L. E., Flack R. D. A flexible rotor on flexible bearing supports: stability and unbalance response. Journal of Vibration and Acoustics, 123(2), 137-144, (2001). https://dx.doi.org/10.1115/1.1355244

4 Sinou J. J., Villa C., Thouverez F. Experimental and numerical investigations of a flexible rotor on flexible bearing supports. International Journal of Rotating Machinery, 2005(3), 179-189, (2005). https://dx.doi.org/10.1155/IJRM.2005.179

5 Sinou J. J., Villa C., Thouverez F., et al. Experimental analysis of the dynamical response of a flexible rotor including the effects of external damping. Journal of Engineering and Applied Sciences, 1(4), 483-490, (2006).

6 Nagasaka I., Ishida Y., Liu J. Forced oscillations of a continuous asymmetrical rotor with geometric nonlinearity (major critical speed and secondary critical speed). Journal of Vibration and Acoustics, 130(3), 031012, (2008). https://dx.doi.org/10.1115/1.2890734

7 Dikmen E., van der Hoogt P., de Boer A., et al. A flexible rotor on flexible supports: modeling and experiments. ASME 2009 International Mechanical Engineering Congress and Exposition. American Society of Mechanical Engineers Digital Collection, 51-56, (2010). https://dx.doi.org/10.1115/IMECE2009-10851

8 Jalali M. H., Ghayour M., Ziaei-Rad S., Shahriari B. Dynamic analysis of a high speed rotorbearing system. Measurement, 53, 1-9 (2014). https://dx.doi.org/10.1016/j.measurement.2014.03.010

9 Birchfield N., Singh K. V., Singhal S. Dynamical structural modification for rotordynamic application. ASME 2013 International Design Engineering Technical Conferences and Computers and Information in Engineering Conference. American Society of Mechanical Engineers Digital Collection, (2014). https://dx.doi.org/10.1115/DETC2013-13509

10 Nagesh S., Basha A. M. J., Singh T. D. Dynamic performance analysis of high speed flexible coupling of gas 
turbine engine transmission system. Journal of Mechanical Science and Technology, 29(1), 173-179, (2015). https://dx.doi.org/10.1007/s12206-014-1224-x

11 Sinou J. J., Thouverez F. Experimental study of a flexible rotor and its dependency on the rolling-bearing temperature. International Journal of Rotating Machinery, 38595, 1-8, (2006). https://dx.doi.org/10.1155/IJRM/2006/38595

12 Lazarus A., Prabel B., Combescure D. A 3D finite element model for the vibration analysis of asymmetric rotating machines. Journal of Sound and Vibration, 329(18), 37803797, (2010). https://dx.doi.org/10.1016/j.jsv.2010.03.029

13 Sopanen J., Heikkinen J., Mikkola A. Experimental verification of a dynamic model of a tube roll in terms of subcritical superharmonic vibrations. Mechanism and Machine Theory, 64, 53-66, (2013). https://dx.doi.org/10.1016/j.mechmachtheory.2013.01.009

14 Wang S., Wang Y., Zi Y., et al. A 3D finite element-based model order reduction method for parametric resonance and whirling analysis of anisotropic rotor-bearing systems. Journal of Sound and Vibration, 359, 116-135, (2015). https://dx.doi.org/10.1016/j.jsv.2015.08.027

15 Zou D., Liu L., Rao Z., et al. Coupled longitudinaltransverse dynamics of a marine propulsion shafting under primary and internal resonances. Journal of Sound and Vibration, 372, 299-316, (2016). https://dx.doi.org/10.1016/j.jsv.2016.03.001

16 Zhou S. H., Song G. Q., et al. Nonlinear dynamic analysis of coupled gear-rotor-bearing system with the effect of internal and external excitations. Chinese Journal of Mechanical Engineering, 29(02), 281-292, (2016). https://dx.doi.org/10.3901/CJME.2015.1019.124

17 Hu L., Palazzolo A. Solid element rotordynamic modeling of a rotor on a flexible support structure utilizing mimo support transfer functions. ASME Turbo Expo 2016: Turbomachinery Technical Conference and Exposition. American Society of Mechanical Engineers Digital Collection, 2016. https://dx.doi.org/10.1115/GT2016-57012

18 Yang R., Hou L., Jin Y., et al. The varying compliance resonance in a ball bearing rotor system affected by different ball numbers and rotor eccentricities. Journal of Tribology, 140(5), 051101, (2018). https://dx.doi.org/10.1115/1.4039566

19 Heidari H., Safarpour P. Optimal design of support parameters for minimum force transmissibility of a flexible rotor based on $H_{\infty}$ and $H_{2}$ optimization methods. Engineering Optimization, 50(4), 671-683, (2018). https://dx.doi.org/10.1080/0305215X.2017.1351560
${ }^{20} \mathrm{Li}$ Y., Cao H., Tang K. A general dynamic model coupled with EFE MODEL and DBM of rolling bearing-rotor system. Mechanical Systems and Signal Processing, 134, 106322, (2019). https://dx.doi.org/10.1016/j.ymssp.2019.106322

21 Zheng Z., Xie Y., Zhang D. Numerical investigation on the gravity response of a two-pole generator rotor system with interval uncertainties. Applied Sciences, 9(15), 3036, (2019). https://dx.doi.org/10.3390/app9153036

22 Zhong Y., He Y., Wang Z. Rotordynamics. Tsinghua University Press, 8: 176-190, (1987).

23 Kurvinen E., Viitala R., Choudhury T., Heikkinen J., Sopanen J. Simulation of subcritical vibrations of a large flexible rotor with varying spherical roller bearing clearance and roundness profiles. Machines, 8(2), 28, (2020). https://dx.doi.org/10.3390/machines 8020028

24 Harris T. A., Kotzalas M. N. Rolling bearing analysisessential concepts of bearing technology, fifth ed., Taylor and Francis, New York, (2007).

25 Liu J., Xu Y., Pan G. A combined acoustic and dynamic model of a defective ball bearing. Journal of Sound and Vibration, 501, 116029, (2021). https://dx.doi.org/10.1016/j.jsv.2021.116029

26 Liu J., Shao Y.. An improved analytical model for a lubricated roller bearing including a localized defect with different edge shapes. Journal of Vibration and Control, 24(17), 3894-3907, (2021). https://dx.doi.org/10.1177/1077546317716315

27 Liu J., Tang C., Wu H., et al. An analytical calculation method of the load distribution and stiffness of an angular contact ball bearing. Mechanism and Machine Theory, 142, 103597, (2019). https://dx.doi.org/10.1016/j.mechmachtheory.2019.103597

28 Liu J. A dynamic modelling method of a rotorroller bearing-housing system with a localized fault including the additional excitation zone. Journal of Sound and Vibration, 469, 115144, (2020). https://dx.doi.org/10.1016/j.jsv.2019.115144

29 Liu J., Shao Y. Dynamic modeling for rigid rotor bearing systems with a localized defect considering additional deformations at the sharp edges. Journal of Sound and Vibration, 398, 84-102, (2017). https://dx.doi.org/10.1016/j.jsv.2017.03.007 